\section{Kim Williams}

Via Cavour, 8

10123 Turin (Torino) Italy

kwilliams@kimwilliamsbooks.com

\section{Pietro Nastasi}

Dipartimento di Matematica Università di Palermo

Via Archirafi, 34

90123 Palermo ITALY

nastasi@math.unipa.it

Keywords: Mario Salvadori, Mauro Picone, Istituto per le Applicazioni del Calcolo, numerical analysis

Research

\title{
Mario Salvadori and Mauro Picone: From Student and Teacher to Professional Fellowship
}

Abstract. The correspondence between Mario Salvadori and Mauro Picone during the years 1934-1972 sheds light on the history of the Italian Institute for the Applications of Calculation. The IAC was a groundbreaking institution for mathematics in Italy, and great attention was given to the new means of mechanical calculation, first analogue, then electronic. It was in relationship to this that Mario Salvadori consulted with his former professor. The correspondence allows us to see also how that relationship changed from one of student-teacher to one of fellowship between professionals.

The books and individuals from whom I have learned what I know of numeric calculus are too numerous to list here, but I wish to express now my gratitude to Prof. Mauro Picone, director of the Istituto Nazionale per le Applicazioni del Calcolo (the Italian laboratory for applied mathematics which will house the International Center of Mechanical Calculus, recently founded), who was the first to teach me to love numbers while I was his student at the University of Rome some 20 years ago.

M. Salvadori, Preface to Numerical Methods in Engineering, New York, Prentice-Hall, 1952

\section{Introduction}

This year, 2007, marks both the hundredth anniversary of the birth and the tenth anniversary of the death of Mario Salvadori (1907-1997), engineer, educator, and mathematician. It is no exaggeration to say that Salvadori's textbooks on structural engineering formed an entire generation of architects in the United States, and since their translation into other languages, in other nations as well. It also marks an important anniversary for another mathematician, Mauro Picone (1885-1977), who eighty years ago this year founded in Naples the embryo of a group for mathematics that would grow to be the Istituto per le Applicazioni del Calcolo "Mauro Picone" (IAC, the Italian Institute for the Applications of Calculation). It was the first such institute for calculation in the world. In Rome, Viale del Politecnico 137, near the site of the Breccia di Porta Pia (where on 20 September 1870 the State of the Catholic Church was defeated) is the present home of the IAC, founded in Naples in 1927 and transferred to Rome in 1932 under the aegis of Italy's CNR, the National Research Council, when Picone assumed a chair in the Department of Mathematics at the University of Rome.

Nexus Network Journal 9 (2007) 165-184 NEXUS NETWORK JOURNAL - VOL. 9, NO. 2, 2007165 
A fortuitous (and fortunate) circumstance - that is, the accidental discovery of the basements of the Roman headquarters of the $I A C$, and in those basements, the rich documentation of past undertakings of the Institute - has allowed us to shed new light on the activities of Mauro Picone and his collaborators, including Mario Salvadori, who played a major role. The historic archives of the $I A C$, recently brought to light by the present director, Prof. Michiel Bertsch and edited by Maurizio Mattaliano, includes among other documents - many letters exchanged by Picone and Salvadori between the years 1934 and 1972. This is one fundamental source for the present paper, which will trace the relationship between the two men. The other fundamental source is Salvadori's unpublished autobiography, entitled $A$ Tangential Life. ${ }^{1}$

Mauro Picone and Mario Salvadori knew each other well, for Picone had been first Salvadori's professor and then thesis advisor at the University of Rome. In 1934, the year after Salvadori earned his doctorate in mathematics, he assumed a part-time position at the $I A C$ under the direction of Picone.

This collaboration would turn out to be precious for both: Salvadori represented a window to the Anglo-Saxon scientific world due to his mastery of the language, and the $I A C$ represented for Salvadori an excellent means of introduction into that world, where he quickly learned how to make his scientific merits appreciated. World events were interrupt Salvadori's career path, and take him from Italy to the United States. In spite of this, the professional lives of the two would remain close, and they remained close personally as well.

\section{Mario Salvadori}

Best known as a practicing engineer on the one hand and educator and author of textbooks of structural mechanics and engineering on the other, Salvadori was actually as much a mathematician as an engineer. Salvadori's early passions were music and mountain climbing, two activities frowned upon by his family. Mathematics was certainly not his first love; he writes, "Like the dishes one hates as a child and learns to like in later years, mathematics did not come naturally to me, but ended up by playing an important role in my life" [p. 3.1]. He describes four phases of his mathematical studies: the first, before he was seven years old; the second, when he was home-schooled by his father, Riccardo, an engineer; the third, his degree work in civil engineering; the fourth, his degree work in pure mathematics. Too intimidated to tell his father that he didn't grasp the concepts he presented to him, Salvadori writes, "I began first to fear and then to hate math" [p. 3.1]. Although he secretly wished to study music, dreaming of becoming an orchestra conductor, he bowed to pressure from his father and enrolled at the University of Rome in 1925 in engineering. The degree program was divided into two parts. The first two years were common to all specialties. His professors during this time there were of the highest caliber: he studied analytical geometry with Guido Castelnuovo (1864-1952); calculus with Francesco Severi (1879-1961); with Tullio Levi-Civita (1873-1941) he studied undergraduate rational mechanics. The last three years were directed toward particular fields; Salvadori's choice was civil engineering. As he describes the program:

...[T]he curriculum in civil engineering was both basic and wide: it emphasized structures and civil works (roads, canals, dams), but included fairly encompassing courses in electrical and mechanical engineering, and in

166 Kim Williams and Pietro NASTASI - Mario Salvadori and Mauro Picone 
architectural design. We were thus better rounded technologists than the students of a contemporary American school [p. 16.21].

But he gives a rather laconic reason for choosing civil engineering: " $[\mathrm{M}] \mathrm{y}$ mild interest in structures was so great in comparison with my complete lack of interest in all other subjects..." [p. 16.22]. He found the professors during the last three years to be uninspiring; among them were Anselmo Ciappi and Aristide Giannelli. He earned his degree in 1930 (the Italian laurea being equivalent to the doctorate in the United States). Of this first accomplishment he writes,

In retrospect my successful graduation from the school of engineering was quite an achievement, because civil engineering at the school was $80 \%$ mathematics and I still did not really understand it. I could go mechanically through some mathematical proofs, knew some applied mathematics techniques, could even formulate some physical problems in mathematical terms, but the essence of the game still escaped me... [p. 3.4].

Announcing to his parents that he would never practice engineering, he decided to begin anew with a graduate course of study in pure mathematics. The reason will surprise many: "What started the fourth phase of my mathematical studies was not an attraction to math as much as a repulsion to engineering" [p. 3.4]. With the irony and humor that were typical of him, he writes,

I also felt that since I had a block against mathematics I could either get psychoanalyzed or find out what mathematics really was. The second option being cheaper and more productive, I decided to get a doctorate in pure mathematics [p. 3-5].

It was then that his love for mathematics blossomed. He once again studied with Castelnuovo, this time in the theory of probability, and with Mauro Picone in numerical analysis. He studied nuclear physics and thermodynamics with Enrico Fermi [Salvadori 1997, 23; 1987, 57]. He mentions that he studied with Federigo Enriques (1871-1946), but doesn't give specifics. His first idea for a doctoral thesis was an application of mathematics to an engineering problem involving dams, but Levi-Civita discouraged him from this [p. 3.10]. His doctoral thesis, under the direction of Mauro Picone, concerned the calculus of variations [p. 3.12].

Salvadori's description of his gargantuan efforts to complete the thesis is as charming as it is telling. With a draft in hand, he went to Selva di Cadore in the Dolomites during August holidays in 1933 to consult with Picone in order to finish it:

In the ten days I spent there with Picone I got the best lesson in mathematical rigor and the most painful humiliation of my entire life. It seems that the proofs of all my theorems, of which there were twelve, were wrong. With almost sadistic pleasure Picone found holes in each one of them. Not irremediable mistakes negating the value of the thesis as a whole, but minor inaccuracies, small non-sequiturs, little stumblings in logic, which he fixed easily enough, but not without first rubbing-in his amazement at my amateurishness. I panicked because of my stake in finishing the thesis on time, but most because I needed his esteem for the future of my career. [...] 
After ten days of mathematical agony I was on the brink of a nervous breakdown, when a miracle occurred: the proof of my last theorem was wrong, of course, but Picone could not find the right proof. I was elated and terrified [p. 3.13].

Salvadori worked through September and into October to find the one example for which the theorem was true. The insight necessary to finish the thesis came in a flash around the middle of October, and thus he earned his Ph.D.

Salvadori was under particular pressure to finish the thesis, because he had to be in London on 1 November 1933:

I had just won an international competition a fellowship that was going to pay for my stay at University College, London, to do graduate work for an academic year under professor E.G. Coker, the inventor of a practical method for evaluating stresses in structures by means of polarized light, photo-elasticity. The fellowship had been granted originally by the League of Nations, but at the time the League had taken the unprecedented action of "sanctioning", that is, of siding against Italy because of her undeclared and bloody war in Ethiopia, and Mussolini had forbidden the acceptance of such grants by Italian citizens, offering instead identical grants from the Fascist government [p. 3.14]. ${ }^{2}$

This is perhaps the first hint of how political events would crucially shape Salvadori's decision to leave Italy for the United States. It was during the eight months in London that Salvadori became aware of how the outside world viewed Italy's Fascist dictatorship, and just how dangerous Mussolini himself and his regime was for Italians. He also met and talked to German refugees fleeing from Nazism, and their stories made a deep impression. But he was generally lonely in London and looked forward to returning to Italy. His future there looked particularly rosy: he could look forward to two part-time positions that would further his career, one with the Istituto per le Applicazioni del Calcolo under the direction of his former thesis advisor, Picone, and the other as assistant to his former professor in civil engineering, Giannelli.

\section{Mauro Picone's IAC}

Picone is universally recognized as the founder of a flourishing Italian school of mathematical analysis and as an exceptional organizer. Among other things, it is to Picone that we owe the autonomous development of numerical analysis and of automated calculation (one of the first computers in Italy was that installed in Rome in 1954 and inaugurated the following year).

Sicilian by birth, Picone studied first in Parma and then in Pisa, where he earned his degree in 1907 at the Scuola Normale Superior, which had been revitalized after Italy's political reunification in the second half of the nineteenth century. A student of Ulisse Dini (1845-1918), a mathematician famous for his rigorous purism, Picone received his illumination "on the road to Damascus" during the course of World War I from 19151918 , an experience which radically changed his way of "viewing mathematics". In particular, the elaboration of new gunnery tables for the artillery - which he achieved by adapting the old tables developed by Francesco Siacci (1839-1907) to the particular geographic conditions of the region around Trento - lead him to write in his 
autobiography, “... you can imagine, after this success achieved with mathematics, the kind of new light in which it appeared to me. I thought: so Mathematics is not only beautiful, it can be useful as well."

After the war, Picone taught at the universities of Turin, Cagliari, Catania, Pisa, Naples and, finally, Rome, becoming known even at an international level. It was in Naples that, in 1927, he founded a small "Istituto di Calcolo", which would then follow its founder to the capital in 1932, to become the Istituto Nazionale per le Applicazioni del Calcolo (INAC). The adjective "National" was dropped in 1969, when the $I A C$ was officially named after its founder.

Salvadori described Picone's founding idea thus:

Picone, a vivacious, bright and aggressive Sicilian had been the first mathematician in Italy to recognize the importance of numerical analysis, a branch of mathematics concerned with approximate calculations and requiring only the use of the four elementary operations of arithmetic. A simple example will explain the gist of numerical analysis to the most unmathematical person. Let us assume that we wish to compute the square root of 5 (a high-school nightmare) and do not remember how to take square roots. Numerical analysis starts by noticing that 2 is not a bad approximation for the square root of 5 since the square of 2 is 4 , a number fairly near 5 , but smaller than 5 . It is then noticed that since 5 divided by 2 , that is, 2.5, is too large an approximation (the square of 2.5 is 6.25), the average of 2 and 5 divided by 2 will probably be a better approximation. The average of 2 and 2.5 is 2.25 and its square is 5.0625. We are almost there, but 2.25 is still a bit too large. If one wants ever better approximations of the square root of 5 , one must simply continue taking the average of the last approximation and of 5 divided by it. In our example, at this stage, we take the average of 2.25 and of 5 divided by 2.25 and obtain 2.236 whose square 4.9997 differs from 5 by only 0.0003 , that is by 3 hundredths of $1 \%$ and has been obtained by adding and dividing numbers only.

When Picone became interested in numerical analysis the electronic computer was twenty-five years into the future and the pure mathematicians at the University of Rome despised the subject, although the Germans had already given it high status in some of their universities. With admirable single mindedness and great political skill Picone succeeded in getting appointed to a chair of mathematical analysis in Rome, left Naples University together with his brilliant assistant Miranda and, besides teaching the kind of math acceptable to his illustrious colleagues, obtained a small grant from the newly established Italian National Research Council to start in a small apartment in Rome in a new section of town the highsounding "Institute for the Applications of the Calculus." (The words "numerical analysis did not appear in the name of the institute and for good reasons [p. 3.10-11].

The $I A C$ immediately became an significant and original force in the Italian scientific panorama. It was the first time that mathematical research had been organized outside the 
rigid academic circuit; it was the first time that young researchers were directed through a channel that led to a considerable number of jobs (in relation to pre-existing conditions); it was the first time that Mathematics became both the subject and the object of consultancies, opening the way to new professional relationships. The changes that Picone was able to effect were not limited to structural and organizational aspects but involved the contents of research and the very meaning of the terms used when we say that we want to undertake and resolve a mathematical problem. A new numerical mentality had appeared on the Italian mathematical horizon. It was no longer sufficient to prove an existence theorem, and ultimately its uniqueness, but rather it was necessary - in an equally essential way - to articulate constructive procedures for calculating the solution. In other words, it was necessary to give the same attention and the same rigor to the determination of a numeric algorithm, for the proof of its convergence and for the margin of error of the approximation. All of this was accompanied almost naturally by a great attention to automated calculation, at first analogical and then, after the second World War, electronic.

Today the $I A C$ is one of the CNR's two main centers of research in applied mathematics. The second center is the IMATI, the Institute for Applied Mathematics and Information Technology, with offices in Genoa, Milan, and Pavia. Since 2002 the IAC has had offices in four cities - Rome, its historic headquarters, Bari, Florence, and Naples - and now has a staff of some fifty-five researchers, plus students, fellows and external collaborators. Since its inception its object has been to develop mathematical, statistical and computer methods for resolving problems of great social and industrial relevance, within an interdisciplinary context.

\section{Picone and Salvadori}

It was precisely regarding the field of automated calculation that Picone turned to Salvadori. Taking advantage of Salvadori's presence in London, who had gone to there to for post-doctoral study in photoelasticity, Picone entrusted him with two projects, as described in a letter of 3 May 1934:

Dear Salvadori,

With the commissions that I am entrusting to you with this letter begins your involvement with this Institute, as I have long desired.

First commission

The Cambridge Instrument Company (45 - Grosvenor Place - London SW1) is the builder of the Mallock machine, which resolves systems of linear equations. The acquisition of such a machine by the Institute, given its elevated cost (some 100,000 Italian lire), must be preceded by a conscientious examination of the machine itself and by testing. I am entrusting all of this to you. I beg you therefore to go to this company, which has been informed of your visit, and to examine the entire functioning of the machine and to understand as much as is possible of the practicality of the operations necessary to guarantee its working as it should. As regards the testing of the machine, the best way is to make it resolve systems of equations to which we already know the solutions; attached to

170 Kim Williams and Pietro Nastasi - Mario Salvadori and Mauro Picone 
this letter are two such systems, which also have the characteristic of symmetry, which is the discriminate of a quadratic form defined as positive.

Once the two systems have been resolved you can send us the solutions which we will compare with our own.

\section{Second commission}

We have been asked to trace isostatic lines relative to the equilibrium of a rhombus-shaped plate with the acute angle measuring $60^{\circ}$ supported on two opposite sides and subject to a uniformly-distributed load. Now we are wondering whether if our formulae for approximations are sufficient and I pose to you the question: is it possible to measure isostatic lines photographically using photo-elastic methods? If it is possible I urgently beg you to involve the institute where you are studying in this problem, which is of extreme importance to us.

Of equal interest is Salvadori's answer, given by return post in a letter dated 7 May 1934:

\section{Most dear Professor,}

At the same time that I thank you for the trust you have shown me, I hasten to tell you the results of my visit to the Cambridge Instrument Company.

I received your letter this morning and discussed the matter with Prof. E.G. Coker, director of the laboratory where I work, who introduced me to the director of the department of statistics of our College, Prof. Pearson. ${ }^{3}$ Prof. Pearson does not know the Mallock machine, but has written me a letter of introduction to Mr. Whipple, one of the general directors of Cambridge Instrument. I went to that company, and in the absence of Mr. Whipple, spoke to his assistant.

The Mallock machine is the fruit of a collaboration with Prof. Mallock of Cambridge and Mr. Mason, general director of Cambridge Instrument; there exists a single exemplar, in the possession of Mr. Mallock, in Cambridge; it is not a machine that is easy to market, indeed one for the Institute for Calculation would be the second one ever built. I cannot therefore have, as I had hoped, information from a body that has been in possession of the machine for some time. I had the systems of linear equations that you sent me sent today to Cambridge; Mr. Mason will resolve them as soon as possible, and I will probably go personally next week to Cambridge, so I can have an accurate explanation of how the machine functions by Mr. Mason or Mr. Mallock. Further, I intend to personally resolve at least one of the two systems so that I have an idea of the rapidity and the greater or lesser simplicity of the operations. As soon as the values obtained are available I will send them to you.

The price of the machine is 1,725 pounds (equal to 103,500 Italian lire), with consignment in any English port; the expenses of packing and customs fall to the buyer. This price, according to Cambridge Instrument, barely covers the cost of manufacture. 
I await any further instructions before going to Cambridge.

Thus began, with a commission of great trust, the consulting activities of Mario Salvadori for Mauro Picone and for the $I A C$.

Once back in Rome, at the IAC under Picone's direction, Salvadori worked on mathematical problems with practical applications for industry, state and science, applications that were looked down upon by the pure mathematicians at the universities.

The only calculators available to us then were mechanical and hand cranked. Later we were able to buy a few electrically powered mechanical calculators, which were a little faster and less noisy. Yet by 1935 Picone's vision and persistence had given the institute, by now the National Institute for the Applications of Calculus, the entire top floor of the new palace of the National Research Council and enough money to pay (miserly) a staff of thirty. As engineering consultant, a part-time job that took half of my time, I made 600 lire or $\$ 30$ a month. On the morning of the inauguration of the new headquarters we were requested to be at our desks at 8 a.m. When "il Duce" strutted along the corridor of the institute we cranked our machines by hand as fast as we could after setting all the levers of our calculators at the 9 positions, because in this configuration the calculators made the biggest racket. Il Duce could not miss the enormous significance to the future of the Fascist Empire of so many 999,999,999s being so loudly multiplied by 999,999,999. In a sense the bombast of these multiplifications was an honest representation of the empty racket of most Fascist activities. As I vigorously turned my crank I saw from the corner of my eye paunchy Mussolini in his black uniform followed by paunchy Picone in his black shirt. As soon as "he" left the racket stopped and we went back to our serious pioneering work [p. 3.11].

Salvadori's other part-time position was assistant to his former professor, Giannelli. He was less fortunate in his choice of mentor in Giannelli than with Picone. Giannelli was fearful of seeing his assistants outstrip their master, and he purposely foiled Salvadori's progress by slowing down publications by him and by delaying his attainment of the qualification of libero docente (a qualification that permits one to teach at university level without a permanent position as professor), which he in any case obtained in 1936 [Salvadori 1987, 59]. But finally Giannelli asked Salvadori to take his place for a lecture, and Salvadori discovered that he not only delighted in lecturing, but that he had a real talent for it. The subject of that first lecture was on the Hardy Cross distribution method [cf. Eaton 2006] for designing buildings in reinforced concrete [p. 16.23]. In just a short time, Salvadori would meet Cross himself during a trip to the United States during which he presented the work of the $I A C$ to colleagues and institutions on the other side of the Atlantic.

\section{Rising tension in pre-war Italy}

In 1938, Giannelli had a new reason to keep Salvadori at a distance. On 17 January, a statement by the Fascist government appeared in all papers claiming that there was no Jewish problem in Italy but reserving the right to limit activities of the Jews as they saw fit. One was considered Jewish if both parents were Jews, or if there had been overt Jewish 
behavior (such as marrying according to a Jewish rite, or belonging to a Jewish community). Salvadori's mother was Jewish, but his father was Catholic, so according to "the laws" he wasn't a Jew. But he was in fact a member of the synagogue, and had been married in a Jewish ceremony. He might not have to have been afraid, but he was. Recalling what he had heard in London from the German Jews fleeing Hitler, he says, "if I had been horrified then, I was terrified now" [p. 21.3].

At first the situation was so unclear that no one knew quite what to do. The question of precisely what kind of activities might be limited was secretly discussed among Jews. The first racial laws appeared in September 1938; these were progressively reinforced as the year went on. Salvadori saw his dream of being a university professor slipping away. To some of those close to him, this seemed almost a minor problem:

My in-laws were so blind that to ignore the obvious they did not even have to bury their heads under the sand. There was nothing to fear; at most I might not be allowed to teach at the University. And so what? I was an engineer, wasn't I? I could be a professional man ... [p. 21-4].

The laws continued to tighten restrictions on the activities of Jews: on 2 September all Jewish high school and university professors were dismissed from their posts. Within a few days, Salvadori was involved twice in racial queries. First he received a telephone call from an embarassed Picone telling him that he should stay away from the $I A C$ for a few days as his "Aryanity" was being investigated [p. 21.10]. Next he received notice regarding his position at the university as Giannelli's assistant, and again his position was suspended until his racial status could be determined [p. 16.23-24]. Not without misgivings and apprehension, and to the consternation of his family, Salvadori resolved to leave Italy as soon as an opportunity presented itself.

That opportunity arrived when Salvadori took part in a competition for a grant to study the organization of television in either the United States or Great Britain so that the Fascist government could organize their own system [p. 20.57]. One of the three members of the competition commission was Enrico Fermi; Salvadori credits Fermi with intervening on his behalf [Salvadori 1987, 59]. He was able to obtain six-month tourist visas for himself and his wife, Giuseppina, effective 16 September, and booked passage on a steamship that sailed six days later. He also proposed to Picone that he officially represent the $I A C$ at the fifth Congress of Applied Mechanics to take place held in that same month in Cambridge, Massachusetts, an offer that Picone accepted. In the historic archives of the Institute there exists a report that Salvadori sent to Picone on 15 November 1938. This is a very important document, because its official tone and account of events is very different from the account of the same events given in his autobiography:

Having decided to go to the United States with a grant from the Institute for Cultural Relations with Foreign States with the object of studying the American organization of television, Prof. M. Picone, Director of the National Institute for Applications of Calculation accepted my proposal of undertaking promotion of the Institute in the spheres of the universities and industries of the United States. To this end I proposed a presentation at the Fifth International Congress of Applied Mechanics in Cambridge, Mass. (USA), on the activities of the National Institute for Applications of Calculation, a report that was written by me in English and which was one 
of the papers accepted for publication in the proceedings of the Congress by the directive committee, which in April declared its enthusiasm for the initiative taken and held that the report would have been received with the greatest interest.

Some difficulties that arose when it was time to obtain the authorization for exporting currency from the Institute for Exchange, prevented me from leaving Italy in time to participate in the Cambridge congress and read the report relative to the Institute at the congress itself. In spite of this, the paper was transmitted to the directive committee, which will see to its publication within the first months of 1939.

As things stood, I was able to leave Italy on 22 September on the steamer Rex and reached New York on 29 September. On 30 September I submitted the participation fee for the congress to the directive committee, which gave me the right to publish the report, letting it be known that I would go to Cambridge personally to tend to the details of the publication.

Because I was without a letter of introduction, I thought it opportune to go at once to the American Society of Civil Engineers in my position of engineer and university professor, with the aim of making contact with the principle New York universities via the most important engineering society. I had the pleasure of meeting, in the absence of the Secretary, the ViceSecretary General Eng. C.E. Beam and the Vice-Secretary Prof. Eng. A. Richmond, professor at Columbia University, to whom I expressed my wishes after having illustrated the aims of the Institute. The very cordial reception on the part of the Secretaries of the A.S.C.E, who were enthusiastic about our organization, permitted me to perform all of my successive activities profitably.

Eng. Richmond immediately arranged an appointment for 3 October for me with Prof. Eng. R.D. Mindlin, professor of elasticity and photoelasticity at Columbia University. This university, the most important in New York and one of the largest and most important in the United States, educates 40,000 students and has a teaching staff of 3900 professors and assistants.

Prof. Mindlin was pleased to invite me to lunch in the name of the university and was extremely interested in my exposition of the activities of the Institute, declaring that to his knowledge there were no such institutes in the United States and asking many for many details about calculation techniques and problems treated by the INAC. I also learned that the name of the INAC and my own were very well known as a result of the prepublication of the proceedings of the Congress mentioned above and that the fact that I was unable to make my presentation was much regretted. I was then invited by Prof. Mindlin to visit his laboratory of photoelasticity as well as the laboratory for material testing, whose Director was also very interesting in the object of my visit. Finally, I had the honor of being introduced to the Dean of the Engineering School, Prof. J.K. Finch, and to Prof. J.M. Garrelts, professor of structural mechanics, to whom I briefly explained the activities of the INAC. 
The next day Prof. Mindlin wanted to me to come again to Columbia University, as a guest of the university, in order to have lunch with Prof. L.P. Siceloff, professor of calculus there, who was very enthusiastic about the INAC and asked for specific information regarding the mathematical methods we use. I gave both Prof. Mindlin and Prof. Siceloff a complete series of the notes of the INAC that I had brought to America, receiving in exchange their own interesting publications.

The report then continues with descriptions of similar meetings with department heads and professors, many of whom were internationally known, at other universities in the United States, including Princeton, Yale, and Harvard. One such meeting must have excited him greatly, for at Yale he met the engineer Hardy Cross, whose distribution method for designing structures in reinforced concrete had been the subject of his firstever university lecture, as mentioned earlier. The report describes the meeting thus:

Yale University enlivens the city of New Haven with its characteristic colleges in the English style, in which students live, going to study in the various faculties. Prof. Hardy Cross, one of the most noted American cultivators of Science of Construction and author of a famous method for the resolution of hyperstatic frame systems which I myself was the first to make known in Italy in 1933, has taught Science of Construction at Yale for a little more than a year, being called there from the University of Illinois. He received me in his studio on 10 October for a lunch in the company of Prof. Krinine, professor of the theory of foundation soils, and his assistant, Dr. Palladino, of Italian origin, and showed me the most cordial hospitality. First of all they presented me to the Dean of the Faculty of Civil Engineering, Prof. S.D. Dudley, to whom I explained the purpose of my visit and who told me that in the name of the University he was honoured to meet a representative of Italian Universities and the Institute of Calculation, for which he had great admiration both as organizations and for their results, and saying how very sorry he was that a previous engagement prevented him from lunching with us.

I visited the Faculty buildings, and was treated to lunch at the University Club, during which I briefly described our methods of calculating. Prof. Cross very much appreciated the contributions made by the l'Istituto Nazionale per le Applicazioni del Calcolo (INAC) to pure and applied science and demonstrated to me two problems, the first connected to his method of calculating frames, and the second to the calculation of arches in reinforced concrete, to which he had given his attention without, however, achieving conclusive results, given that they were of a specifically mathematical nature. I proposed to Prof. Cross that we place the problems in the hands of the INAC and he was very enthusiastic about this collaboration with Italian scientists.

Dr. Palladino was courteous enough to escort me to visit the buildings of the main colleges, and then to take me back to Prof. Cross, who wished to introduce me to his class of graduate students, presenting me with many flattering words about the Institute. Naturally I left with Prof. Cross a 
complete series of notes from the Institute, receiving in return copies of his interesting publications.

The report then includes a description of a lecture that he was invited to give at 8:30 on the evening of 27 October at Columbia University, preceded by a dinner in his honor, just two days before his departure for Italy:

At dinner Prof. Mindlin, Prof. Garrelts, Prof. Biot and Prof. Nervmann were present. Prof. Siceloff introduced me in the name of Prof. Finch, who was away from New York, to an audience of more than 50 people, some of whom were professors, others of whom were professionals. My lecture dealt with the same material that had formed the object of my paper for the Cambridge Congress, complete with many details and extended in scope, since the communication for the congress had had a limit on length.

At the end of the lecture, which lasted more than three-quarters of an hour, I had the opportunity to respond to numerous questions of technical and general nature by about ten members of the audience, and to distribute the remaining copies of the publications of the Institute that I had reserved for the occasion. A professor of chemistry at Columbia University wished to pose to me an important query regarding mathematics applied to chemistry, and begged me to subject it to the study of the INAC. Among others, present at the lecture were two of my former students at the University of Rome (Drs. Ripetto and Calandra), as well as two professors of Italian origin at City College of NY. The lecture was concluded with thanks by Prof. Garrelts in the name of the School.

On 28 October, the day before my departure, I was introduced to Prof. J.W. Barker, Dean of all the schools of engineering at Columbia University, and to Prof. Pegram, Dean of the School of Physics and of that specialization of the same university. These two personages as well demonstrated keen interest in the work of the Institute, during a cordial interview.

Salvadori concludes his report with six points:

a) the publication of the paper presented at the Cambridge Congress will make the work of the INAC known to the American scientifictechnological world, which demonstrated during the Congress the keenest interest in our organization;

b) the promotion made personally by the undersigned in academic circles aroused the most unconditional admiration for the informing ideas and the practical actuation of our Institute, as is clear from the statements of no less than 27 professors, some of which are very well-known academic personages of international acclaim;

c) there does not exist in the United States any specific organization with the aims of the INAC, as I was told repeatedly in all the scientific and academic milieus that I frequented, even though individual mathematical

176 Kim Williams and Pietro NaStASI - Mario Salvadori and Mauro Picone 
consultants for industry and some institutions can in very particular cases fill this need;

d) even though the American industrial organization is partially equipped for the theoretical resolution of many problems and admirable equipped for their experimental resolution, a collaboration between the INAC and American institutes and industries would be possible. One fruit of this brief visit was the beginning of this collaboration in the scientific arena;

e) the exchange of publications between the INAC and the American institutes should favor the acquaintance with the Institute on the part of American technological-scientific organizations;

f) the expressions of sincere and lively admiration of the INAC on the part of many and diverse persons demonstrates in an evident way that the Institute by now enjoys a well-deserved fame of an international nature, which reflects the glory of the National Council for Research and Fascist Italy.

The closing remark of this letter shouldn't be surprising: this is an official, written report at a moment in which the personal situation of many Italian Jews was unclear. But the description in the official report is a far cry from Salvadori's account of it in his autobiography.

In the official report, he describes meeting Raymond Mindlin, but doesn't mention that Mindlin was also a Jew to whom Salvadori confided his predicament, and that Mindlin was ready to help Salvadori leave Italy permanently and set up a new life in the United States. Mindlin and Salvadori established a code by which Salvadori could communicate with Mindlin by letter after returning to Italy. If the situation was as dire as Salvadori feared it might be, he would write to Mindlin saying that his illness was worse and couldn't be cured in Italy, and if Mindlin was able to help, he would answer Salvadori saying that medicine was available in the United States and that Salvadori should come over for a cure. After having taken the precaution of hiring a safe-deposit box in a bank, leaving all of his wife's jewels in it, and giving a copy of the key to Mindlin, Salvadori returned to Italy to see which way the wind was blowing. Even the purpose of the lecture he was invited to give at Columbia two days before his departure was not so much intended to inform the audience about the activities of the $I A C$ as much as it was for Columbia professors to judge Salvadori's qualifications:

I was unaware of the fact that, in a country in which professors are not chosen by competition, seminars are often used to test the qualifications of a person aspiring to join the faculty. Ray had organized the meeting very skillfully and I don't believe I let him down [p. 21.24].

Indeed, the situation was as bad as Salvadori had feared. An official notice of temporary suspension from the $I A C$ pending verification of his racial status arrived in November 1938 [p. 21.27], just a few days after his return from the United States, during which visit he had acted as an official representative of Italy and the IAC. Salvadori wasted no time. He wrote the official report for Picone about the contacts that he had made while acting as representative of the $I A C$ to industries and universities. He wrote the official report for the Ministry of Communications about his meeting with the president of the Radio 
Corporation of America, and he ascertained that the visas granted on 16 September were still valid for re-entry to the United States. After that, he gathered what he could to take with him and said good-bye to friends and family.

Salvadori and his wife arrived in New York on 13 January 1939 to begin a new life. The very next day, a wire reached him saying that his suspension due to racial reasons had been rescinded. He wrote, "It was my incredible luck to receive such news the day after my arrival in New York" [p. 21.32].

\section{Overseas contact}

Almost a year would pass before Salvadori contacted Picone. In a letter dated 5 November 1939 he wrote:

I am truly sorry and wish to apologize for not having resume contact with you until today, but first of all the confusion of life in America, and then my illness have physically kept me from doing so. My father has kept me regularly informed about the progress of my business with the Council (CNR), and has recently sent me the letter of dismissal from the Secretary General.

By uncanny coincidence this letter reached me on the same day in which I began work as an engineer in an important factory in New Jersey, but even this does not prevent me from confessing my disappointment at being removed from your Institute for which I have worked for four years, and from which I have learned so much and to which I hope that, within the modest limits of my capabilities, I have given what has been asked of me.

But above all I regret that I must leave you, to whom I owe so much, and my dear colleagues.

As you yourself have observed my situation has not followed the course that was shown and promised to me. The head of personnel of the CNR has not held my position sufficiently transparent, and it would seem that he has seen fit to dismiss me from the Institute because of my trip, in spite of my explicit declaration that I would return within the month of March and your disposition to await me until April.

All told perhaps it is better that this has happened, because my reception in New York and the offer of the position that I currently hold have contemporarily made me decide to stay in the United States. The interesting nature of the work in a large American factory, with a starting salary that is four times what I was earning in Rome and is rapidly increasing, the vast possibilities of this country, combined with the not total acceptance of who I am, due to occurrences beyond your control and mine, would have forced me to tender my resignation, though I would have done so with regret. I am therefore grateful that the Secretary General found the best solution of all.

In spite of my occupation of an industrial nature, I am still in contact with the various universities and would very much like to receive regularly the publications of the Institute, so that I can continue the promotional work 
that began so well. If I could receive news about you personally I would be most happy.

I beg you to give my most cordial greetings to all the colleagues of the Institute, and to tell them of my good news, and for yourself please accept this expression of fond gratitude from your devoted student.

The occupation "of an industrial nature" to which Salvadori refers was with the Lionel Train Company, the largest American manufacturer of toy trains. By the 1940-1941 academic year he had already been assigned a course in "applied mathematics for engineers" at Columbia University.

Picone solicited him to establish scientific relations between the Department of Civil Engineering" of Columbia University and the $I A C$. But the second World War interrupted every possibility of this happening. It is significant, however, that at the end of the war, in 1945, Salvadori remembered his former teacher and the IAC and sent to Picone in Rome, via his father Riccardo, the following communication in a letter dated 7 November 1945:

We also want to develop an electric machine to solve problems of vibrations and another, of which a small version has already been constructed by a mathematics professor at Columbia, to solve linear algebraic equations. This man got the idea of solving the equations with a machine that is so simple and so inexpensive that any ham radio operator could build it at home ... and he did so by means of an idea that is simply delightful. If it functions for many equations as simply as it does for now for four, the problem that science has been posing for many years ... will be resolved ... and with very little money, so that I would be happy to write a report in Italian so that you could build one over there.

But at that time Picone was already involved in one of his most important projects, that which, following the liberation of Rome in 1944, would engage him in the attempt to bring Italy and the $I A C$ to the level achieved by the great industrial powers in the field of instruments for calculation. Picone's long campaign for the construction or acquisition of the "first great Italian electronic calculators", which concluded in 1954, represents one of the few successful attempts in Italy in the direction of scientific and technological innovation.

Picone had learned of the construction of the first American computer from an article dated 4 August 1944 in The Stars and Stripes, the newspaper of the American armed forces in Europe. He immediately began to campaign for one, but the post-war political conditions - the beginning of the period that we usually call "the cold war" - were such that only in 1954 could his dreams become reality, when with a contribution from the funds provided by the Marshall Plan he was able to acquire a computer from the firm named Ferranti in England. During this decade, Salvadori assisted Picone with assiduous, caring, and intelligent advice, in exchange for which the INAC carried out the execution of various calculations that were helpful in promoting Salvadori's image as an engineermathematician. It can safely be said that Salvadori's role of ambassador was a significant factor in realizing the dream to which his former professor rightly attributed such importance. Picone himself attests to this in his address during the 1955 inauguration of the commencement of service of the FINAC, as was called the Mark I computer that 
Ferranti constructed purposefully for the Institute (the acronym is a combination of $\mathrm{F}$ for Ferranti with the INAC of the Institute):

Once peace was established after the last war, news arrived in Italy, fragmentary and imprecise as the reports were, of great calculating machines, of immeasurable power, which had been constructed in the United States during the war for military purposes. Thus was born in my soul, and in those of my colleagues, the hope that we would come to own one of those machines, so that we could obtain concrete solutions to all the problems that awaited them.

From that moment we have tenaciously pursued that goal, and after many missions abroad - facilitated by cordial receptions wherever we went - after having tested the majority of the new calculating machines, whose construction in the meantime was being undertaken and perfected in several of the most technologically advanced nations, we were finally able to select and obtain for our use the powerful electronic calculator that we today solemnly inaugurate, in the esteemed and heartening presence of the Head of State (...)

Our experiences thus far with this calculator have deeply convinced us that the considerable expense sustained by the State for its acquisition will most certainly, in the right hands, be amply compensated for by the benefits that its well-planned employment will produce in terms of the scientific and industrial progress of our Nation.

With the arrival of the computer, the already flourishing collaboration between the $I N A C$ and Mario Salvadori was strengthened, and Salvadori could propose to the INAC forms of collaboration that extended to other colleagues and institutions in the United States. Thus for example in a letter of 9 October 1956, Salvadori wrote:

\section{Dearest Picone,}

I am so sorry to have only seen you for such a short time last summer, but I am counting on being there again next summer and to talking to you at leisure.

The American Society of Civil Engineers has informed me that they could send the Institute 450 copies of my published report on the critical loads of fixed beams for $\$ 140.00$. I would be grateful to you if your could let me know if you want them, or given the cost, if you would want a smaller number.

I came back to New York two weeks ago and have resumed my work. An engineer colleague of mine, who works on thin shells, has asked me to ask you how much it would cost to solve a system of 100 equations with 100 unknowns (linear, naturally). I don't believe that this constitutes an academic research, and therefore the Institute must be compensated. I would be grateful if you could send me an answer. 


\section{A final decision}

In spite of his success in the United States both as a professor at Columbia University and as a practicing structural engineer, Salvadori and his wife struggled to decide whether or not to return to Italy now that Fascism no longer threatened and a lasting peace had been restored. Picone himself had solicited Salvadori about this possibility several times. In a personal and confidential letter dated 6 April 1957, Salvadori expressed both his desire and his difficulties to his former teacher. That by this time their relationship had outgrown the limits of student and teacher and had become one of affectionate equals is evident from the use in the original Italian of the informal "tu" instead of the formal "Lei" that Salvadori had formerly used to address Picone. He wrote:

We are counting on leaving for Italy on 12 June and hope to see you as soon as we reach Rome, towards the end of June, but before then I hope to be able to ask you some questions of a general nature, of the kind that one can only ask of a beloved teacher whose friendship is precious.

As you know, I have been a full professor for some years at Columbia University and further, for the past two years I have been assigned to teach courses in structural mechanics at the school of architecture at Princeton University. My professional practice has been going strong for the past two years, since I went into partnership with a brilliant American engineer, ${ }^{4}$ with whom we design daring structures for the best architects here, and undertake research in the dynamics of structures for the American Government. Thus I couldn't be more fortunate in my American career, from an academic and professional as well as from an economic point of view. But you know me and you know my family, and it won't surprise you if I tell you, naturally in the strictest confidence, that in our heart of hearts Giuseppina and I still hope to return to Italy. On the one hand I would be loathe to return if I had failed in the United States, and on the other hand the desire to return has been tempered by the success I've had here. This is why, in spite of the affectionate encouragement recently, I had never determined to open up to you, which I now do in hopes that you will have some fatherly advice for me.

I just turned 50 a few days ago and know, or believe I know, that teaching is probably out of the question for me in Italy, even though I am still enrolled in the register of teachers of the University of Rome. You know that for many years I have continued researching in mechanics and structures and that I have some 60 publications to my credit, plus 3 books on applied mathematics, of which the first was published in Italy as well and the second (on numerical calculus) translated into Russian, Portuguese, and Chinese (although this last is not yet published). I believe that you know that I speak 5 [languages] and Romanian. And now here is the question: what kind of work and occupation could I find in Italy, if I decided to return?

It is obvious that I cannot accept some minor position, and that I wish to perform an activity that gives me deep satisfaction, in addition to a dignified income. I am too aware of my very modest worth to add that I 
wish to make a contribution to Italian scientific life, but I do not hide that a position in which my knowledge of the international scientific world could result in even a small contribution to our nation would attract me more than any other.

I am completely in the dark regarding the regulations of universities and public and semi-public institutes, and I have no idea what industry might offer me. I think because of your knowledge and contacts with the scientific and industrial spheres and because of your affection for me, and because of your wisdom, you are the only person in Italy to whom I can turn and who can give me dispassionate and caring advice. I thus await your answer, and wish to express now my profound gratitude.

In his answer Picone suggests several solutions that range from possible rehiring at the INAC in his former role as "consultant" to participation in a competition for a chair in structural mechanics at the University of Palermo. Salvadori opted for this last, and participated in the competition, qualifying for the position (along with two other Italian colleagues). He hoped to be called to the University of Florence, where in 1959 a position was supposed to become available. But this hope was not to be realized because Salvadori had lost his Italian citizenship in July 1940 (as we are informed in a letter dated 17 February 1958). He therefore remained in the United States. But he was deeply disappointed, even if it didn't arrest his extraordinary capacity for work. Here is what he wrote to Picone in a letter dated 5 October 1958:

By this time you will have learned of the negative outcome of my competition: after having received the decree nominating me from the Ministry, it was taken away because I was unable to show that I was an Italian citizen on the day that I enrolled in the competition. Dr. Di Domizio, General Director of Secondary Education, was extremely nice during a long interview, but he could do absolutely nothing, given the Italian laws concerning nationality and the rules of the competition.

The dream of returning to Italy as a professor has thus vanished, after months of hope and anguishing doubts, and nothing remains for me now but to stay in America.

I still have the possibility of beginning a professional role as engineering consultant in Italy, and this I will begin to do. I have a consultancy with Olivetti concerning its mechanical calculators, and consultancies of a structural nature with groups of architects. Indeed, I have opened an office in Rome together with a group of American engineers, which I will tell you about when I see you.

I am now leaving for the United States, where I am going to give three lectures, in addition to a lecture in Madrid en route. I will be in Rome again on 21 October, and together with my family, will pass the whole year at Via Michele Mercati 10, Tel 870-295.

It was perhaps good for Mario Salvadori but a great loss for Italy that this is how things went. But this judgment is part of another story! 


\section{Acknowledgment}

The authors wish to thank Michael Kazin, Mario Salvadori's stepson, for having provided us with a copy of the autobiography $A$ Tangential Life.

\section{Notes}

1. Page references provided in the text for quotations from Mario Salvadori refer to this autobiography.

2. We believe that Salvadori makes a slight error here, anticipating the international isolation of Italy by some years.

3. Egon Sharpe Pearson (1895-1980), son of the well-known Karl Pearson (1857-1936).

4. Paul Weidlinger (1915-1999).

\section{References}

Eaton, Leonard. 2006. Hardy Cross: American Engineer. Champaign IL: University of Illinois Press. Salvadori, Mario. n.d (1977?). A Tangential Life. Unpublished. 65. 1987. Ricordando Enrico Fermi (Memorie di un non-fisico). Il Nuovo Saggiatore 1, 3: 541997. A Life in Education. The Bridge 27, 2 (Summer 1997): 21-27.

\section{About the authors}

Kim Williams received her degree in architecture from the University of Texas in Austin. She practiced architecture in New York City until 1987, when she moved to Italy. She is the director of the conference series "Nexus: Relationships Between Architecture and Mathematics" and editor-inchief of the Nexus Network Journal. Her books include Italian Pavements: Patterns in Space (Houston, Anchorage Press, 1997) and The Villas of Palladio (New York, Princeton Architectural Press, 2003).

After beginning in physics, Pietro Nastasi earned his degree in mathematics in 1965 with a thesis on the application of Stieltjes integrals for the calculation of mathematical reserves in life insurance. His early scientific studies regarded positional geodesic astronomy and climatology in the area of Palermo. From the end of the 1970s, he has dedicated more and more of his research to the history of mathematics, a discipline that he has taught as Associate Professor since 1985 at the Faculty of Sciences of the University of Palermo. In this area of research, from his first studies on "local history" his principle interests have been progressively oriented towards more general themes and are presently focused on the study of institutional aspects of Italian mathematics after the unification of Italy. Among his studies are those dedicated to the repercussions of the racial laws on the Italian scientific world, and is the co-author (with Giorgio Israel) of Scienza e razza nell'Italia fascista (Bologna, 1998), and co-author (with Angelo Guerraggio) of Italian Mathematics Between the Two World Wars (Springer, 2006). 
